\title{
A systematic review of randomized controlled trials of bupropion versus methylphenidate in the treatment of attention-deficit/ hyperactivity disorder
}

\author{
Narong Maneeton' \\ Benchalak Maneeton' \\ Suthi Intaprasert ${ }^{1}$ \\ Pakapan Woottiluk ${ }^{2}$ \\ 'Department of Psychiatry, Faculty \\ of Medicine, ${ }^{2}$ Psychiatric Nursing \\ Division, Faculty of Nursing, Chiang \\ Mai University, Chiang Mai, Thailand
}

Correspondence: Benchalak Maneeton Department of Psychiatry, Faculty of Medicine, Chiang Mai University, Amphur Muang, Chiang Mai 50200, Thailand

Tel +66 53945422

Fax +66 $53217 \quad 144$

Email benchalak.maneeton@cmu.ac.th
This article was published in the following Dove Press journal: Neuropsychiatric Disease and Treatment

I August 2014

Number of times this article has been viewed

Background: Some trials have suggested that bupropion, as well as methylphenidate, is beneficial in the treatment of attention-deficit/hyperactivity disorder (ADHD).

Objectives: The purpose of this systematic review was to summarize the efficacy, acceptability, and tolerability of bupropion in comparison with methylphenidate for ADHD treatment. Included studies were randomized controlled trials (RCTs) that compared bupropion and methylphenidate. Clinical studies conducted between January 1991 and January 2014 were reviewed.

Data sources: MEDLINE ${ }^{\circledR}$, EMBASETM $^{\mathrm{T}}$ CINAHL, PsycINFO ${ }^{\circledR}$, and the Cochrane Controlled Trials Register were searched in January 2014. Additionally, clinical trials were identified from the databases of ClinicalTrials.gov and the EU Clinical Trials Register.

Study eligible criteria, participants, and interventions: All RCTs of bupropion and methylphenidate reporting final outcomes relevant to 1) ADHD severity, 2) response or remission rates, 3) overall discontinuation rate, or 4) discontinuation rate due to adverse events. Language restriction was not applied.

Study appraisal and synthesis methods: The relevant clinical trials were examined and the data of interest were extracted. Additionally, the risks of bias were also inspected. The efficacy outcomes were the mean changed scores of ADHD rating scales, the overall response rate, and the overall remission rates. The overall discontinuation rate and the discontinuation rate due to adverse events were determined. Relative risks and weighted mean differences or standardized mean differences with $95 \%$ confidence intervals were estimated using a random effect model. Results: A total of 146 subjects in four RCTs comparing bupropion with methylphenidate in the treatment of ADHD were included. The pooled mean changed scores of the Iowa-Conner's Abbreviated Parent and Teacher Questionnaires and the ADHD Rating Scale-IV for parents and teachers of children and adolescents with ADHD in the bupropion- and methylphenidatetreated groups were not significantly different. Additionally, the pooled mean changed score in adult ADHD between the two groups, measured by the ADHD Rating Scale-IV and the Adult ADHD Rating Scale, was also not significantly different. The pooled rates of response, overall discontinuation, and discontinuation due to adverse events between the two groups were not significantly different.

Conclusion: Based on limited data from this systematic review, bupropion was as effective as methylphenidate for ADHD patients. Additionally, tolerability and acceptability were also comparable. However, these findings should be considered as very preliminary results. To confirm this evidence, further studies in this area should be conducted.

Keywords: bupropion, methylphenidate, systematic review, ADHD, acceptability, tolerability 


\section{Background}

Attention-deficit/hyperactivity disorder (ADHD) is a common psychiatric problem for children and adolescents through to adults. The worldwide prevalence rate is $5.29 \%,{ }^{1}$ with $5 \%-10 \%$ for children and adolescents ${ }^{2,3}$ and $2.5 \%-4.4 \%$ for adults. ${ }^{3,4}$

As a neurodevelopmental disorder with executive function deficits, ${ }^{5,6} \mathrm{ADHD}$ affects academic achievement in individuals with ADHD. Although a decline in ADHD symptoms into adulthood is observed, persistence of inattention is often seen in several patients. ${ }^{7,8}$ In addition, ADHD in childhood may be linked to working disabilities in adults. ${ }^{9}$

Methylphenidate, a psychostimulant, was considered to be a primary treatment for ADHD. ${ }^{10-12}$ However, up to $40 \%$ of ADHD patients did not respond to methylphenidate. ${ }^{13,14} \mathrm{In}$ addition, some patients encountered adverse events, including decreased appetite and insomnia, ${ }^{15}$ which may have been the cause of discontinuation from this medication. A recent study also suggested that long-term use of methylphenidate was associated with deceleration of height velocity. ${ }^{16}$ For these reasons, its use for the treatment of ADHD may be limited in some patients.

Bupropion, a dopamine and norepinephrine reuptake inhibitor, has been indicated in the treatment of depressive disorder and nicotine dependence. The evidence suggests that it may be effective in the treatment of ADHD patients. Recently, some randomized controlled trials (RCTs) of bupropion have shown its efficacy in child and adolescent ADHD. ${ }^{17}$ In addition, a recent meta-analysis has suggested that bupropion is efficacious in the treatment of adult ADHD. ${ }^{18}$ Although some studies have suggested its efficacy in the treatment of ADHD, physicians may be reluctant to prescribe it for treating those patients, due to limited evidence.

Some RCTs comparing the efficacy and tolerability between bupropion and methylphenidate have been conducted in patients with ADHD. ${ }^{19-22}$ As three of those trials ${ }^{19,20,22}$ had a very small sample size, a systematic review, which is more effective in calculating the true effect size, was a plausible method to examine efficacy, acceptability, and tolerability. Therefore, we performed a systematic review of RCTs of bupropion versus methylphenidate in ADHD patients.

\section{Methods}

The first publications on bupropion and methylphenidate in MEDLINE ${ }^{\circledR}$ were in 1977 and 1956, respectively, ${ }^{23,24}$ and bupropion was first patented in 1969 by the Bur- roughs Wellcome Company, which later became part of GlaxoSmithKline. Consequently, related clinical trials were searched from January 1956 to January 2014.

\section{Eligibility criteria}

Any RCTs of bupropion compared with methylphenidate conducted in ADHD spectrum subjects and presenting scores of ADHD standard rating scales were eligible for review. In addition, response, remission, and discontinuation rates must have been reported. An ADHD spectrum comprised ADHD, attention-deficit disorder, hyperkinetic syndrome, hyperkinetic reaction, minimal brain damage, minimal cerebral dysfunction, or minor cerebral dysfunction diagnosed by any set of criteria. The language of the study was not limited.

\section{Information sources}

The main databases, including MEDLINE ${ }^{\circledR}$, EMBASETM, $^{\mathrm{T}}$ CINAHL, PsycINFO ${ }^{\circledR}$, and Cochrane Controlled Trials Register, were searched in January 2014. Databases searched were restricted to human studies. As GlaxoSmithKline originally produced bupropion, its databases were also searched. The search for any article reference gathered from any source was applied. The relevant studies included for this review were only RCTs and clinically controlled trials (CCTs).

\section{Searches}

For greater sensitivity for searching the RCTs and CCTs, the searching strategies were a combination of the following words and phrases: ([bupropion] OR [Wellbutrin] OR [Zyban] OR [Quomem]) AND ([methylphenidate] OR [Ritalin] OR [Concerta]) AND ([attention-deficit/hyperactivity disorder] OR [ADHD] OR [attention-deficit disorder] OR [hyperkinetic syndrome] OR [hyperkinetic reaction] OR [minimal brain damage] OR [minimal cerebral dysfunction] OR [minor cerebral dysfunction]). This strategy was applied for searching all databases.

\section{Study selection}

To consider whether the articles met the included criteria defined, the identified abstracts of the databases were evaluated by the reviewers (NM and BM) individually. After obtaining the full text articles of relevant studies, the reviewers then individually examined them. Disputes were resolved by consensus.

\section{Data collection process}

After developing a data extraction form, the first reviewer (NM) extracted the interest outcomes into this form. Then, the 
second reviewer (BM) rechecked the extracted details. Any disagreement by the reviewers was resolved by consensus. When a dispute could not be resolved, the third author (SI) played a role in the decision.

\section{Data items}

The essential details extracted from all studies included 1) data for evaluating the study validity; 2) basic data of included subjects; 3 ) criteria used for diagnosis and design of each trial, and inclusion/exclusion criteria; 4) details of bupropion and methylphenidate treatment in terms of forms, doses, and time course; and 5) interesting results. The intention-to-treat outcomes were also collected.

\section{Risk of bias in individual studies}

All included studies were evaluated for the internal validity (quality) by the reviewers (NM and BM). As suggested by the Cochrane Collaboration handbook, ${ }^{25}$ risks of bias for each study were examined as follows: 1) random sequence generation (selection bias), 2) allocation concealment, 3) blinding, 4) incomplete outcome, 5) selective reporting, 6) other sources of bias, and 7) baseline similarity.

\section{Summary measures}

Interesting outcomes consisted of efficacy, acceptability, and tolerability. Efficacy outcomes were the mean change of scores measured by ADHD assessment instruments, and the response and remission rates determined by any criterion. Generally, "acceptability" and "tolerability" may be interchangeable words; in fact, each term had a specific definition. As defined in a previous meta-analysis, the acceptability in our review was measured as the overall discontinuation rate. ${ }^{26}$ The discontinuation rate due to adverse events was designed for measurement of tolerability, regularly examined in the side effects. ${ }^{27}$

Frequently, systematic review applies a statistical technique, so-called meta-analysis, to synthesize the outcomes of included studies. The synthesis for all continuous data was performed by using either weighted mean difference (WMD) or standardized mean difference (SMD) with the $95 \%$ confidence interval $(95 \% \mathrm{CI})$. In cases of the same outcome measure across studies, it was reasonable to directly compare or combine their outcomes by using the WMD. When the same measurement was not plausible, a standardized value for which there was no unit was used for comparison or combination of those results. In this review we computed either the WMDs or the SMDs whether the eligible studies applied the same or different rating scales. The standard deviation (SD) of mean changed score for ADHD rating scale was calculated by performing a directly substituted or any statistical method..$^{28}$

Regularly, the dichotomous results were synthesized by using relative risks (RRs) with $95 \%$ CI. When an RR was 1 , it suggested that there were no differences between the two groups. In the case of an RR of less than 1, it indicated that such an outcome was less likely to occur. For the present review the RRs were applied in the comparison of the response rates, overall discontinuation rates, and discontinuation rates due to adverse events, between the two groups.

\section{Synthesis of results}

As a rule, the data were synthesized by the use of either a fixed or a random effect approach. When the fixed effect model was applied, all included trials were assumed to share a common effect size. In contrast to a random effect model, the variation across studies was ignored. In fact, one true effect size was less likely to occur, although the included trials were relatively similar. Therefore, it was not reasonable to speculate that they were entirely identical. Consequently, all data in this review were synthesized using a random effect model.

\section{Risk of bias across studies}

Generally, a funnel plot can be used for detecting the existence of publication bias in systematic review. It is a simple graph of the intervention effect calculated from each trial against some measure of each trial's size or precision. ${ }^{29}$ For this reason, it was planned to be applied in this review, if possible.

\section{Test of heterogeneity}

To determine whether the study outcomes were similar, a test of heterogeneity was essentially applied. Before performing this review, we hypothesized that all study outcomes did not have the same effect, due to the methodological quality in each trial. We examined the extent of variation among the study results. By observing the outcomes shown by graphic display and using the test of heterogeneity, we determined whether study results had greater differences than were expected by chance alone. In this review, the $\mathrm{I}^{2}$ index was applied for estimation of heterogeneity among trials. In case of an $\mathrm{I}^{2}$ of $50 \%$ or greater, a significant heterogeneity of results was acknowledged.

\section{Statistical software}

In this review, RevMan 5.1 (The Nordic Cochrane Centre, Copenhagen, Denmark) was applied for all analyses. 


\section{Results}

\section{Study selection}

By searching those databases, we obtained 88 total citations $\left(\right.$ MEDLINE $^{\circledR}=$ seven studies, EMBASETM $=$ five studies, $\mathrm{CINAHL}=$ seven studies, PsycINFO ${ }^{\circledR}=57$ studies, Cochrane Controlled Trials Register $=$ eleven studies, ClinicalTrials. gov $=$ one study, and the EU Clinical Trials Register $=$ no studies) (see Figure 1). When duplicate articles were discarded, a total of 71 studies were included. After all of the titles and abstracts were carefully examined, 67 studies were excluded because they did not meet the criteria of RCTs comparing bupropion and methylphenidate. Only four eligible full articles were included and completely assessed. All of them were eligible in this review. ${ }^{19-22}$ There were no relevant and unpublished trials meeting the eligibility criteria for this study.

\section{Study characteristics}

The study duration for the four trials was from 6 weeks to 16 weeks. The longest study duration (16 weeks) was

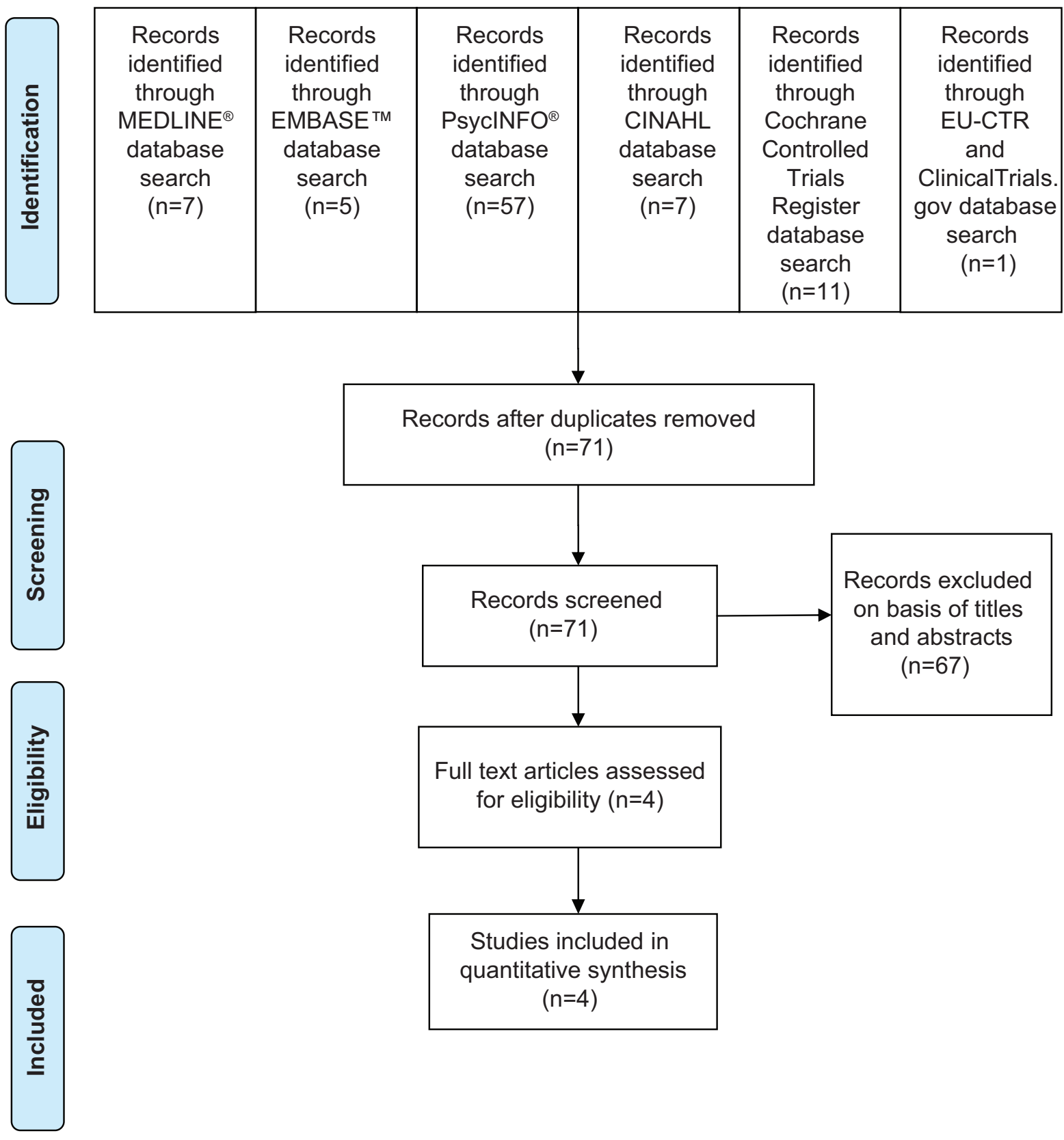

Figure I Flow diagram of study design. 
a crossover design with 2 weeks for a washout period, 6 weeks for each treatment, and 2 weeks for an additional washout period between each treatment. Three trials ${ }^{19-21}$ had washout or medication-free periods (1-2 weeks), and the rest ${ }^{22}$ excluded subjects who had taken psychotropic agents. Two trials ${ }^{20,21}$ were performed in adult ADHD participants and compared bupropion, methylphenidate, and placebo with no significant difference in efficacy. Additionally, one tria $^{21}$ was carried out in methadone-maintained patients with ADHD.

Of 146 randomized subjects, $64.75 \%$ were male. In child and adolescent groups, the mean ages (SDs) for the bupropionand methylphenidate-treated groups were 10.43 (3.15) and 10.60 (2.79), respectively. For adult groups, the mean ages (SDs) were 36.8 (9.03) years and 38.28 (7.16) years, respectively. The dosage of bupropion and methylphenidate ranged from $50-200 \mathrm{mg} /$ day and $20-60 \mathrm{mg} / \mathrm{kg} /$ day for child and adolescent groups, respectively. The basic characteristics of eligible trials are shown in Table 1.

As mean changed scores for ADHD were measured using the different rating scales across those studies, their SMDs were computed and synthesized. Response rates, overall discontinuation rates, and discontinuation due to adverse events were found in three studies. ${ }^{20-22}$

\section{Risk of bias within studies}

All trials used a randomized, double-blind technique. One trial was designed as a double-blind, crossover study. ${ }^{19}$ Only one study applied an intention-to-treat analysis. ${ }^{22}$ Dropout data were shown in three studies, ${ }^{20}$ and baseline similarity was found in all trials. Only one study showed a sequence generation of randomization, ${ }^{22}$ and two trials demonstrated an allocation concealment. ${ }^{19,22}$ Freedom from selective reporting was unclear in all studies. No risk of bias for baseline similarity and other bias were reported in all trials (see Table 2).

\section{Results of individual studies}

For child and adolescent ADHD, the mean changed IowaConner Abbreviated Parent and Teacher Questionnaire $(\mathrm{ICQ})^{30}$ or ADHD Rating Scale-IV (ADHD-RS-IV) ${ }^{31}$ scores for parents and teachers were not significantly different between the bupropion and methylphenidate-treated groups in each study (see Figures 2 and 3). Similarly, the mean changed ADHD-RS or Adult ADHD Rating Scale (AARS) scores for adult ADHD between the two groups were not significantly different in each study (see Figure 4). Additionally, the response rate for adult ADHD in each study

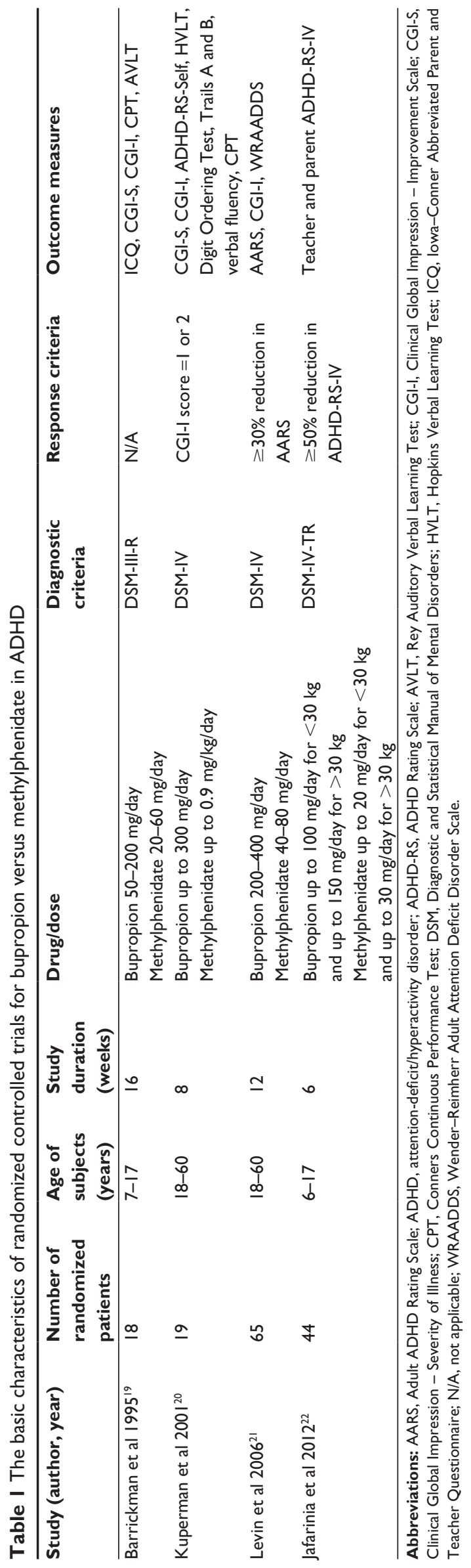


Table 2 Risk of bias summary of controlled trials of bupropion versus methylphenidate in attention-deficit/hyperactivity disorder

\begin{tabular}{|c|c|c|c|c|c|c|c|}
\hline \multirow[t]{2}{*}{ Study (author, year) } & \multicolumn{7}{|c|}{ Issues of bias } \\
\hline & $\mathbf{I}$ & 2 & 3 & 4 & 5 & 6 & 7 \\
\hline Barrickman et al $1995^{19}$ & $U$ & L & L & $U$ & $U$ & L & $\mathrm{L}$ \\
\hline Kuperman et al $200 \mathrm{I}^{20}$ & $U$ & 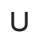 & $u$ & $\mathrm{~L}$ & $U$ & L & $\mathrm{L}$ \\
\hline Levin et al $2006^{21}$ & $U$ & U & L & L & $U$ & L & $\mathrm{L}$ \\
\hline Jafarinia et al $2012^{22}$ & $\mathrm{~L}$ & L & L & L & $U$ & L & $\mathrm{L}$ \\
\hline
\end{tabular}

Notes: I, adequate sequence generation; 2, allocation concealment; 3, blinding (subjective outcome); 4 , dropout data addressed; 5 , free of selective reporting; 6, free of other bias; 7, baseline similarity.

Abbreviations: L, low risk of bias; $U$, unclear.

was not significantly different between the two groups (see Figure 5).

\section{Synthesis of results}

\section{Efficacy}

There was not a significant heterogeneity in each efficacious outcome. The pooled mean changed ICQ and ADHD-RS-IV score for parents and teachers in child and adolescent ADHD in the bupropion- and methylphenidate-treated groups was not significantly different (SMD [95\% CI] of $-0.41[-0.92$, $0.11], \mathrm{I}^{2}=10 \%$, and SMD [95\% CI] of $-0.10[-0.57,0.38]$, $\mathrm{I}^{2}=0 \%$ (see Figures 2 and 3 ). Additionally, the pooled mean changed ADHD-RS and AARS score in adult ADHD in the two groups was also not significantly different (SMD $\left[95 \% \mathrm{CI}\right.$ ) of $-0.38[-0.81,0.06], \mathrm{I}^{2}=0 \%$ ) (see Figure 4$)$. The pooled response rate for adult ADHD between the bupropionand methylphenidate-treated groups was not significantly different (RR [95\% CI] of $1.36[0.84,2.21], \mathrm{I}^{2}=0 \%$ ) (see Figure 5). Finally, the pooled response rate for child and adolescent and adult groups was also not different between two treatment groups (RR [95\% CI] of 1.08 [0.85, 1.38], $\left.I^{2}=15.4 \%\right)($ see Figure 5).

\section{Discontinuation rates}

The pooled overall discontinuation rate in adult ADHD between the bupropion- and methylphenidate-treated groups was not significantly different (RR [95\% CI] of $\left.0.81[0.41,1.61], I^{2}=0 \%\right)$. The pooled overall discontinuation rate in adult ADHD and child and adolescent ADHD between two groups was also not significantly different (RR [95\% CI] of 0.84 [0.45, 1.57], I ${ }^{2}=0 \%$ ) (see Figure 6). The pooled discontinuation rate due to adverse events in adult ADHD between the bupropion- and methylphenidatetreated groups was not significantly different (RR [95\% CI] of $\left.0.25[0.03,2.14], I^{2}=0 \%\right)$. However, pooled discontinuation rate due to adverse events in child and adolescent ADHD between the two groups could not be calculated (see Figure 7).

\section{Risk of bias across studies}

The funnel plot asymmetry was regularly applied for the systematic review with ten or more included trials, as it was hard to distinguish real asymmetry in the case of fewer trials. ${ }^{29}$ For this reason, the funnel plot was not conducted in this review, which included only four studies.

\section{Discussion}

This systematic review found four RCTs of bupropion versus methylphenidate conducted in ADHD patients (two studies for the child and adolescent group and an adult group). According to limited findings, this review suggested that bupropion may be as effective as methylphenidate in the

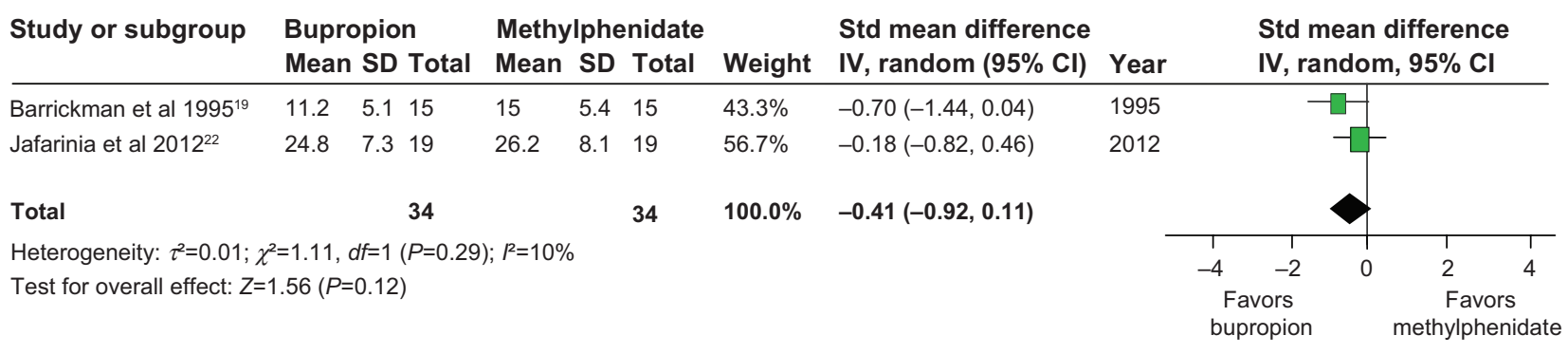

Figure 2 Comparison of the mean changes from baseline of ADHD rating scales for parents of children and adolescents with ADHD: bupropion versus methylphenidate. Abbreviations: ADHD, attention-deficit/hyperactivity disorder; $\mathrm{Cl}$, confidence interval; df, degrees of freedom; IV, inverse variance; SD, standard deviation; Std, standard. 


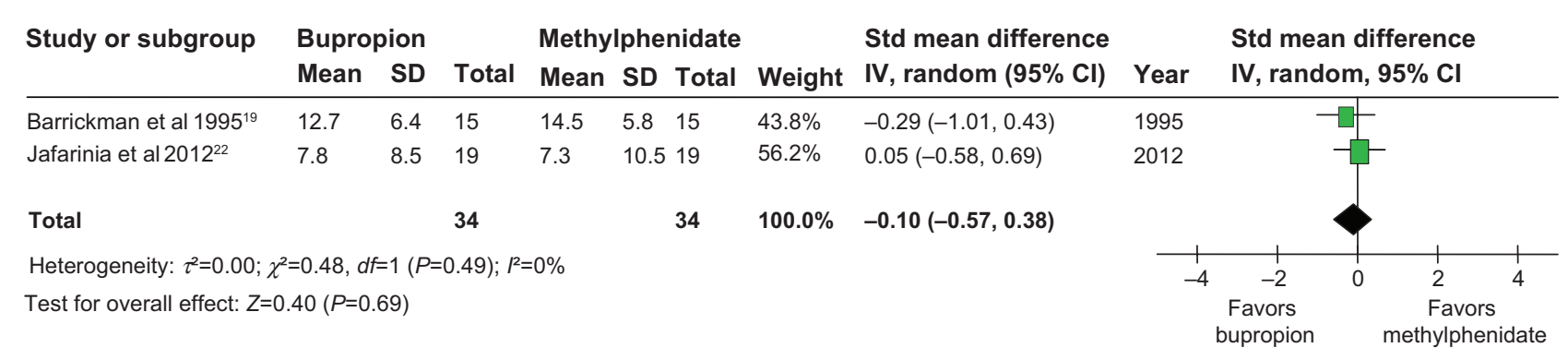

Figure 3 Comparison of the mean changes from baseline of ADHD rating scales for teachers of children and adolescents with ADHD: bupropion versus methylphenidate. Abbreviations: ADHD, attention-deficit/hyperactivity disorder; $\mathrm{Cl}$, confidence interval; df, degrees of freedom; IV, inverse variance; SD, standard deviation; Std, standard.

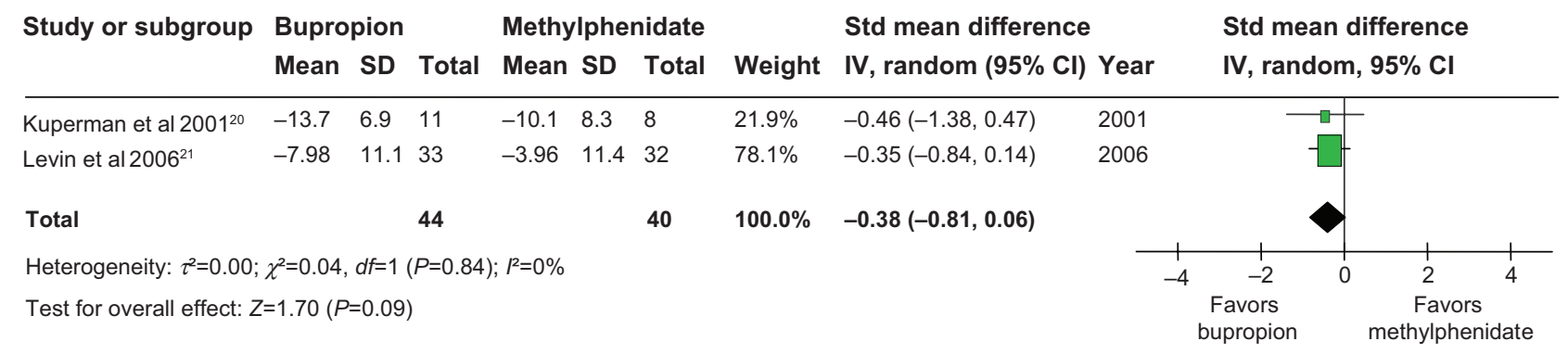

Figure 4 Comparison of the mean changes from baseline of ADHD rating scales in adult ADHD: bupropion versus methylphenidate.

Abbreviations: ADHD, attention-deficit/hyperactivity disorder; Cl, confidence interval; df, degrees of freedom; IV, inverse variance; SD, standard deviation; Std, standard.

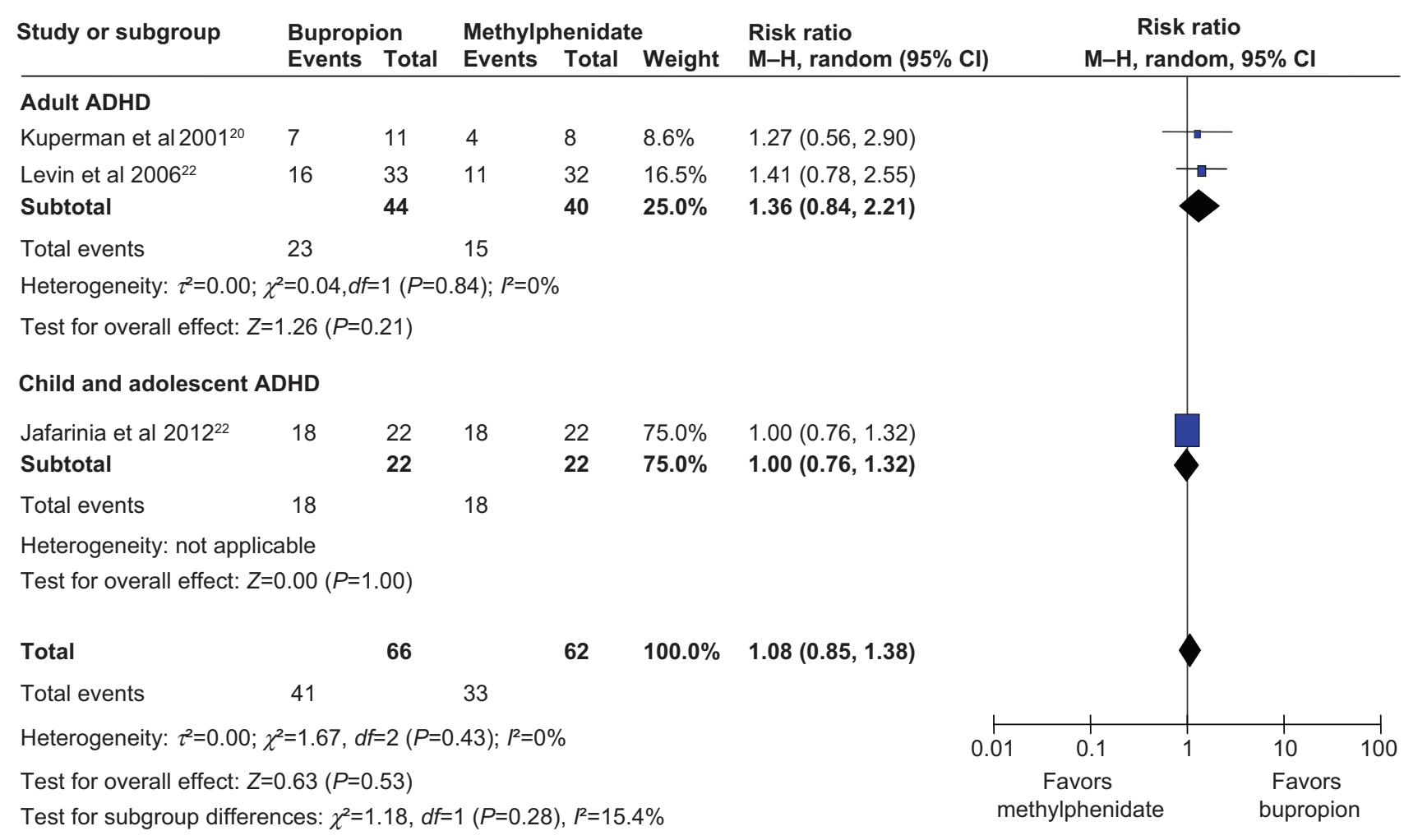

Figure 5 Comparison of relative risk for clinical response rates in ADHD: bupropion versus methylphenidate.

Abbreviations: ADHD, attention-deficit/hyperactivity disorder; $\mathrm{Cl}$, confidence interval; $d f$, degrees of freedom; $\mathrm{M}-\mathrm{H}$, Mantel-Haenszel. 


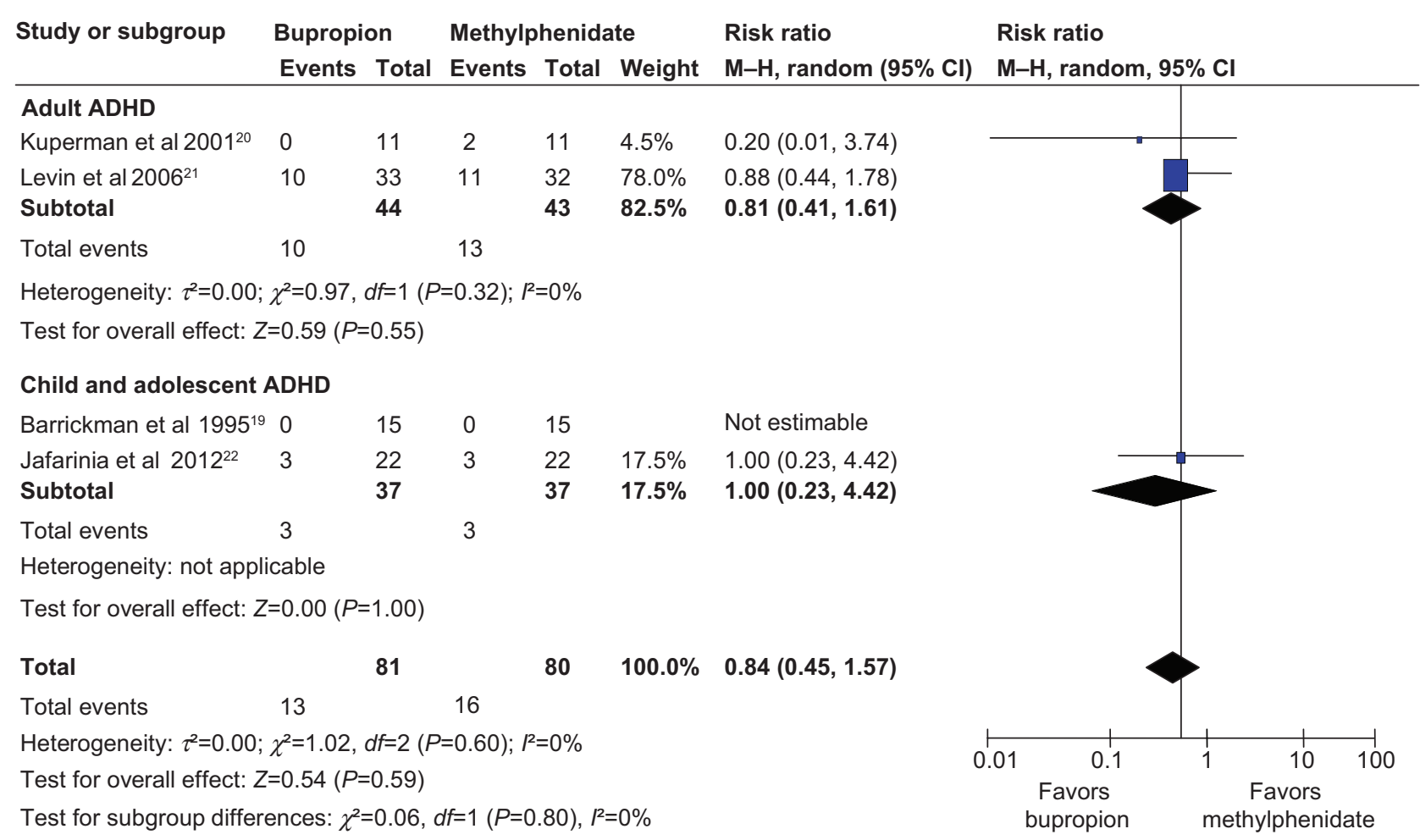

Figure 6 Comparison of relative risk for an overall discontinuation rate in ADHD: bupropion versus methylphenidate.

Abbreviations: ADHD, attention-deficit/hyperactivity disorder; $\mathrm{Cl}$, confidence interval; $\mathrm{df}$, degrees of freedom; $\mathrm{M}-\mathrm{H}, \mathrm{Mantel}-\mathrm{Haenszel}$.

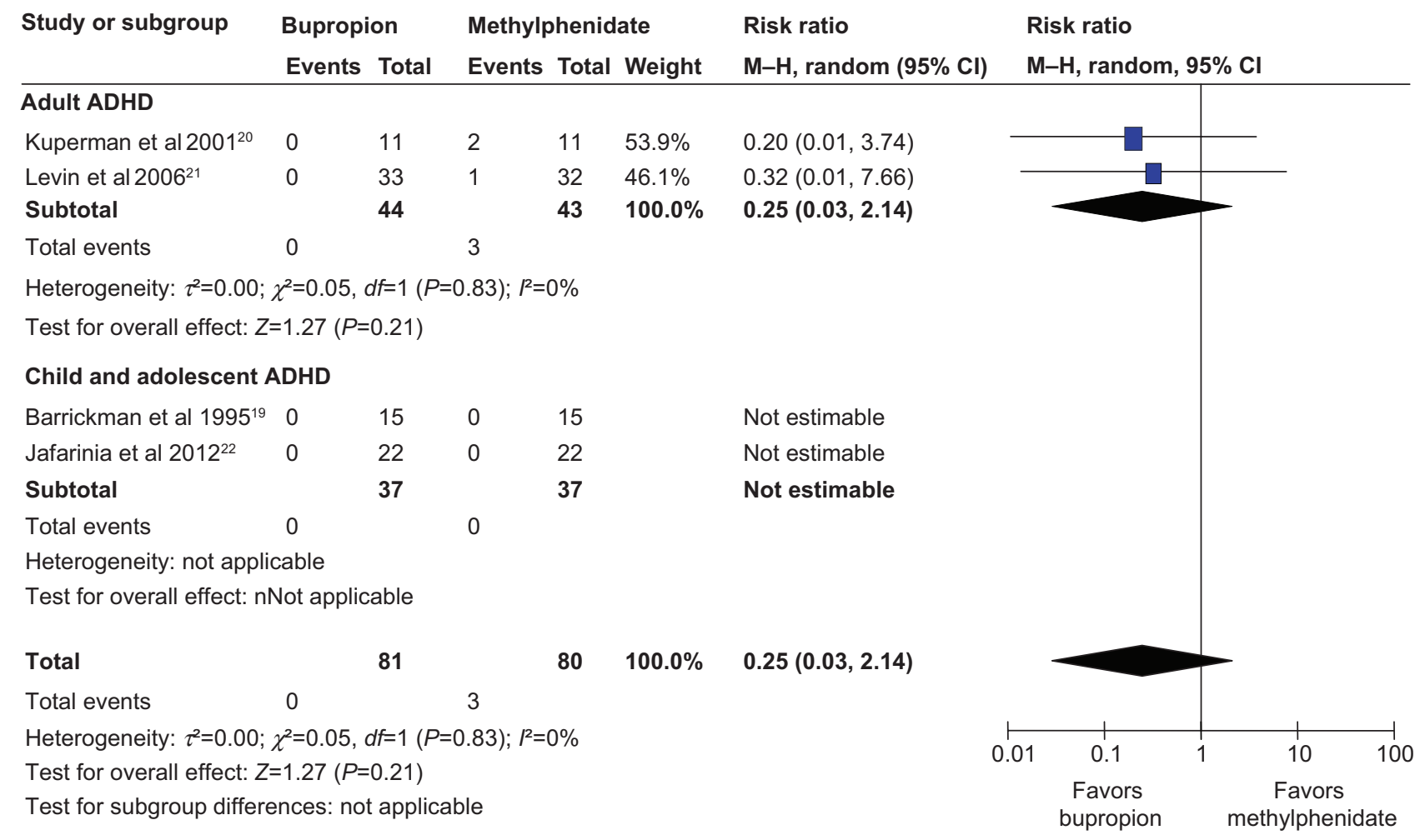

Figure 7 Comparison of relative risk for a discontinuation rate due to adverse events in ADHD: bupropion versus methylphenidate. Abbreviations: ADHD, attention-deficit/hyperactivity disorder; $\mathrm{Cl}$, confidence interval; df, degrees of freedom; $\mathrm{M}-\mathrm{H}, \mathrm{Mantel}-\mathrm{Haenszel}$. 
treatment of ADHD. Additionally, the acceptability and tolerability of active agents were comparable. As there was only a small number of included studies and limited quality of the included studies, these findings should be cautiously interpreted for application in clinical practice.

As a rule, methylphenidate is the first-line treatment for child, adolescent, and adult ADHD. However, some patients did not respond well to methylphenidate, and others could not tolerate its adverse events, particularly poor appetite, insomnia, and headache. ${ }^{22,32}$ In addition, there was more concern about the illegal diversion of it. ${ }^{33,34}$ Therefore, alternative pharmacological treatment in those patients is necessary.

A previous study suggested that several antidepressants are effective in the treatment of ADHD. Desipramine, a tricyclic antidepressant, showed its efficacy in child, adolescent, and adult ADHD. ${ }^{35-38}$ One report indicated sudden death in children using desipramine ${ }^{39}$ and its propensity for induced prolonged PR interval and a significantly higher heart rate in children. ${ }^{40}$ In addition, a small number of studies found that reboxetine, ${ }^{41-43}$ a specific noradrenaline reuptake inhibitor, and venlafaxine ${ }^{44,45}$ were beneficial in the treatment of ADHD. Even if reboxetine and venlafaxine were effective in the treatment of ADHD, several side effects included drowsiness, anorexia, irritability, anxiety, sleep disturbance, and dry mouth. ${ }^{42,43,45}$ Therefore, use of those antidepressants in ADHD patients may be limited.

In this review, acceptability and tolerability between bupropion and methylphenidate were similar to previous studies. Similarly, the study of venlafaxine compared with methylphenidate in child and adolescent ADHD found that there was no dropout in either group of subjects due to an adverse event. ${ }^{44}$ Additionally, another study of atomoxetine and methylphenidate in the treatment of child ADHD also suggested that safety and tolerability of both active agents were comparable. ${ }^{46}$ These lines of evidence may suggest that the tolerability of bupropion and other antidepressants was comparable with methylphenidate.

Even if efficacy acceptability and tolerability of bupropion were comparable with methylphenidate, bupropion may have some advantage over methylphenidate. Although both active agents have a similar pharmacological profile, ${ }^{47}$ bupropion may have less risk of potential abuse. ${ }^{48}$ Additionally, bupropion has a low incidence of adverse events. ${ }^{22,49}$ Thus, bupropion is a possible alternative treatment in ADHD.

Several limitations were found in this review. Firstly, there were a limited number of studies (four RCTs) included in this review. Additionally, one study was performed in methadone-maintained patients with ADHD. Therefore, these findings should be carefully interpreted. Secondly, some studies were sponsored by a pharmaceutical company holding the patent of bupropion. Therefore, these results should be cautiously interpreted. Thirdly, based on the quality assessment, we found that two eligible studies ${ }^{20,21}$ had more than two unclear risks of bias, as they contained a lack of adequate details for the assessment. Fourthly, like all systematic reviews, publication bias must be assessed. Unfortunately, the possibility of publication bias was not assessed, because of a small number of included trials. ${ }^{29}$

\section{Conclusion}

According to this review, bupropion was as effective as methylphenidate in the treatment of ADHD. Additionally, the acceptability and tolerability of both active agents were comparable. Due to a limited number of included studies, these findings should be considered as the preliminary results. Further studies in this area should be conducted to confirm these results.

\section{Acknowledgment}

This review received financial support from the Faculty of Medicine, Chiang Mai University, Chiang Mai, Thailand.

\section{Author contributions}

All authors conceived the idea, prepared the study protocol, prepared the manuscript, and approved the manuscript in its current form. NM and BM searched the databases, extracted the data, and analyzed the data.

\section{Disclosure}

NM has received travel reimbursement from GlaxoSmithKline, Pfizer, Janssen-Cilag, and Lundbeck. BM has received an honoraria and/or travel reimbursement from GlaxoSmithKline and Pfizer. SI and PW report no conflicts of interest in this work.

\section{References}

1. Polanczyk G, de Lima MS, Horta BL, Biederman J, Rohde LA. The worldwide prevalence of ADHD: a systematic review and metaregression analysis. Am J Psychiatry. 2007;164(6):942-948.

2. Montiel C, Pena JA, Montiel-Barbero I, Polanczyk G. Prevalence rates of attention deficit/hyperactivity disorder in a school sample of Venezuelan children. Child Psychiatry Hum Dev. 2008;39(3):311-322.

3. Polanczyk G, Rohde LA. Epidemiology of attention-deficit/hyperactivity disorder across the lifespan. Curr Opin Psychiatry. 2007;20(4) 386-392.

4. Simon V, Czobor P, Balint S, Meszaros A, Bitter I. Prevalence and correlates of adult attention-deficit hyperactivity disorder: meta-analysis. Br J Psychiatry. 2009;194(3):204-211.

5. Barkley RA, Grodzinsky G, DuPaul GJ. Frontal lobe functions in attention deficit disorder with and without hyperactivity: a review and research report. J Abnorm Child Psychol. 1992;20(2):163-188. 
6. Clark C, Prior M, Kinsella GJ. Do executive function deficits differentiate between adolescents with ADHD and oppositional defiant/conduct disorder? A neuropsychological study using the Six Elements Test and Hayling Sentence Completion Test. J Abnorm Child Psychol. 2000; 28(5):403-414.

7. Weiss G, Hechtman L, Milroy T, Perlman T. Psychiatric status of hyperactives as adults: a controlled prospective 15-year follow-up of 63 hyperactive children. J Am Acad Child Psychiatry. 1985;24(2): 211-220.

8. Davidson MA. ADHD in adults: a review of the literature. $J$ Atten Disord. 2008;11(6):628-641.

9. Mordre M, Groholt B, Sandstad B, Myhre AM. The impact of ADHD symptoms and global impairment in childhood on working disability in mid-adulthood: a 28-year follow-up study using official disability pension records in a high-risk in-patient population. BMC Psychiatry. 2012;12:174.

10. Dulcan MK, Benson RS. AACAP Official Action. Summary of the practice parameters for the assessment and treatment of children, adolescents, and adults with ADHD. J Am Acad Child Adolesc Psychiatry. 1997;36(9):1311-1317.

11. Arnsten AF. Stimulants: therapeutic actions in ADHD. Neuropsychopharmacology. 2006;31(11):2376-2383.

12. Mohammadi M, Akhondzadeh S. Advances and considerations in attention-deficit/hyperactivity disorder pharmacotherapy. Acta Medica Iranica. 2011;49(8):487-498.

13. Rosler M, Fischer R, Ammer R, Ose C, Retz W. A randomised, placebocontrolled, 24-week, study of low-dose extended-release methylphenidate in adults with attention-deficit/hyperactivity disorder. Eur Arch Psychiatry Clin Neurosci. 2009;259(2):120-129.

14. Biederman J, Mick E, Surman C, et al. A randomized, 3-phase, 34-week, double-blind, long-term efficacy study of osmotic-release oral systemmethylphenidate in adults with attention-deficit/hyperactivity disorder. J Clin Psychopharmacol. 2010;30(5):549-553.

15. Sonuga-Barke EJ, Coghill D, Wigal T, DeBacker M, Swanson J. Adverse reactions to methylphenidate treatment for attention-deficit/ hyperactivity disorder: structure and associations with clinical characteristics and symptom control. J Child Adolesc Psychopharmacol. 2009;19(6):683-690.

16. Zhang H, Du M, Zhuang S. Impact of long-term treatment of methylphenidate on height and weight of school age children with ADHD. Neuropediatrics. 2010;41(2):55-59.

17. Conners CK, Casat CD, Gualtieri CT, et al. Bupropion hydrochloride in attention deficit disorder with hyperactivity. J Am Acad Child Adolesc Psychiatry. 1996;35(10):1314-1321.

18. Maneeton N, Maneeton B, Srisurapanont M, Martin SD. Bupropion for adults with attention-deficit hyperactivity disorder: meta-analysis of randomized, placebo-controlled trials. Psychiatry Clin Neurosci. 2011;65(7):611-617.

19. Barrickman LL, Perry PJ, Allen AJ, et al. Bupropion versus methylphenidate in the treatment of attention-deficit hyperactivity disorder. J Am Acad Child Adolesc Psychiatry. 1995;34(5):649-657.

20. Kuperman S, Perry PJ, Gaffney GR, et al. Bupropion SR vs methylphenidate vs placebo for attention deficit hyperactivity disorder in adults. Ann Clin Psychiatry. 2001;13(3):129-134.

21. Levin FR, Evans SM, Brooks DJ, Kalbag AS, Garawi F, Nunes EV. Treatment of methadone-maintained patients with adult ADHD: doubleblind comparison of methylphenidate, bupropion and placebo. Drug Alcohol Depend. 2006;81(2):137-148.

22. Jafarinia M, Mohammadi MR, Modabbernia A, et al. Bupropion versus methylphenidate in the treatment of children with attention-deficit/ hyperactivity disorder: randomized double-blind study. Hum Psychopharmacol. 2012;27(4):411-418.

23. Soroko FE, Mehta NB, Maxwell RA, Ferris RM, Schroeder DH. Bupropion hydrochloride ((+/-) alpha-t-butylamino-3-chloropropiophenone $\mathrm{HCl}$ ): a novel antidepressant agent. $J$ Pharm Pharmacol. 1977;29(12):767-770.
24. Barison F, Massignan L. Rassegna di neuropsichiatria e scienze affini [Observations on neurotic depressions with reference to a combined serpasil-ritalin treatment]. Rass Neuropsichiatr 1956;10(5-6):198-209. Italian.

25. Higgins JPT, Altman DG. Assessing risk of bias in included studies. In: Higgins JPT, Green S, editors. Cochrane Handbook for Systematic Reviews of Interventions. Version 5.1.0 (Updated March 2011). The Cochrane Collaboration; 2009. Available from: http://www.cochranehandbook.org. Accessed June 6, 2014.

26. Cipriani A, Furukawa TA, Salanti G, et al. Comparative efficacy and acceptability of 12 new-generation antidepressants: a multipletreatments meta-analysis. Lancet. 2009;373(9665):746-758.

27. Papakostas GI. Tolerability of modern antidepressants. J Clin Psychiatry. 2008;69 Suppl E1:8-13.

28. Wiebe N, Vandermeer B, Platt RW, Klassen TP, Moher D, Barrowman NJ. A systematic review identifies a lack of standardization in methods for handling missing variance data. J Clin Epidemiol. 2006;59(4): 342-353.

29. Sterne JAC, Egger M, Moher D. Addressing reporting biases. In: Higgins JPT, Green S, editors. Cochrane Handbook for Systematic Reviews of Interventions. Version 5.1.0 (Updated March 2011). The Cochrane Collaboration; 2009. Available from: http://www.cochranehandbook.org. Accessed June 6, 2014.

30. Loney J, Milich R. Hyperactivity, inattention, and aggression in clinical practice. In: Wolraich M, Routh DK, editors. Advances in developmental and behavioral pediatrics. Greenwich, CT: JAI; 1982:113-147.

31. Dupaul GJ, Power TJ, Anastopoulos AD, Reid R. ADHD Rating Scale-IV: Checklists, norms, and clinical interpretation. New York: Guilford Press; 1998.

32. Lee J, Grizenko N, Bhat V, Sengupta S, Polotskaia A, Joober R. Relation between therapeutic response and side effects induced by methylphenidate as observed by parents and teachers of children with ADHD. BMC Psychiatry. 2011;11:70.

33. Wilens TE, Adler LA, Adams J, et al. Misuse and diversion of stimulants prescribed for ADHD: a systematic review of the literature. J Am Acad Child Adolesc Psychiatry. 2008;47(1):21-31.

34. Sembower MA, Ertischek MD, Buchholtz C, Dasgupta N, Schnoll SH. Surveillance of diversion and nonmedical use of extended-release prescription amphetamine and oral methylphenidate in the United States. J Addict Dis. 2013;32(1):26-38.

35. Biederman J, Baldessarini RJ, Wright V, Knee D, Harmatz JS. A double-blind placebo controlled study of desipramine in the treatment of ADD: I. Efficacy. J Am Acad Child Adolesc Psychiatry. 1989;28(5): 777-784.

36. Singer HS, Brown J, Quaskey S, Rosenberg LA, Mellits ED, Denckla MB. The treatment of attention-deficit hyperactivity disorder in Tourette's syndrome: a double-blind placebo-controlled study with clonidine and desipramine. Pediatrics. 1995;95(1):74-81.

37. Wilens TE, Biederman J, Prince J, et al. Six-week, double-blind, placebo-controlled study of desipramine for adult attention deficit hyperactivity disorder. Am J Psychiatry. 1996;153(9):1147-1153.

38. Spencer T, Biederman J, Coffey B, et al. A double-blind comparison of desipramine and placebo in children and adolescents with chronic tic disorder and comorbid attention-deficit/hyperactivity disorder. Arch Gen Psychiatry. 2002;59(7):649-656.

39. Riddle MA, Geller B, Ryan N. Another sudden death in a child treated with desipramine. J Am Acad Child Adolesc Psychiatry. 1993;32(4): 792-797.

40. Pataki CS, Carlson GA, Kelly KL, Rapport MD, Biancaniello TM. Side effects of methylphenidate and desipramine alone and in combination in children. $J$ Am Acad Child Adolesc Psychiatry. 1993;32(5): $1065-1072$.

41. Ratner S, Laor N, Bronstein Y, Weizman A, Toren P. Six-week openlabel reboxetine treatment in children and adolescents with attentiondeficit/hyperactivity disorder. J Am Acad Child Adolesc Psychiatry. 2005;44(5):428-433. 
42. Arabgol F, Panaghi L, Hebrani P. Reboxetine versus methylphenidate in treatment of children and adolescents with attention deficithyperactivity disorder. Eur Child Adolesc Psychiatry. 2009;18(1): 53-59.

43. Riahi F, Tehrani-Doost M, Shahrivar Z, Alaghband-Rad J. Efficacy of reboxetine in adults with attention-deficit/hyperactivity disorder: a randomized, placebo-controlled clinical trial. Hum Psychopharmacol. 2010;25(7-8):570-576.

44. Zarinara AR, Mohammadi MR, Hazrati N, et al. Venlafaxine versus methylphenidate in pediatric outpatients with attention deficit hyperactivity disorder: a randomized, double-blind comparison trial. Hum Psychopharmacol. 2010;25(7-8):530-535.

45. Amiri S, Farhang S, Ghoreishizadeh MA, Malek A, Mohammadzadeh S. Double-blind controlled trial of venlafaxine for treatment of adults with attention deficit/hyperactivity disorder. Hum Psychopharmacol. 2012;27(1):76-81
46. Kratochvil CJ, Heiligenstein JH, Dittmann R, et al. Atomoxetine and methylphenidate treatment in children with ADHD: a prospective, randomized, open-label trial. J Am Acad Child Adolesc Psychiatry. 2002;41(7):776-784.

47. Overtoom CC, Verbaten MN, Kemner C, et al. Effects of methylphenidate, desipramine, and L-dopa on attention and inhibition in children with attention deficit hyperactivity disorder. Behav Brain Res. 17, 2003; 145(1-2):7-15.

48. Simmler LD, Wandeler R, Liechti ME. Bupropion, methylphenidate, and 3,4-methylenedioxypyrovalerone antagonize methamphetamineinduced efflux of dopamine according to their potencies as dopamine uptake inhibitors: implications for the treatment of methamphetamine dependence. BMC Res Notes. 2013;6:220.

49. Nieuwstraten CE, Dolovich LR. Bupropion versus selective serotoninreuptake inhibitors for treatment of depression. Ann Pharmacother. 2001;35(12):1608-1613.
Neuropsychiatric Disease and Treatment

\section{Publish your work in this journal}

Neuropsychiatric Disease and Treatment is an international, peerreviewed journal of clinical therapeutics and pharmacology focusing on concise rapid reporting of clinical or pre-clinical studies on a range of neuropsychiatric and neurological disorders. This journal is indexed on PubMed Central, the 'PsycINFO' database and CAS,

\section{Dovepress}

and is the official journal of The International Neuropsychiatric Association (INA). The manuscript management system is completely online and includes a very quick and fair peer-review system, which is all easy to use. Visit http://www.dovepress.com/testimonials.php to read real quotes from published authors.

Submit your manuscript here: http://www.dovepress.com/neuropsychiatric-disease-and-treatment-journal 